\title{
Response assessment in lymphoma with PET/CT
}

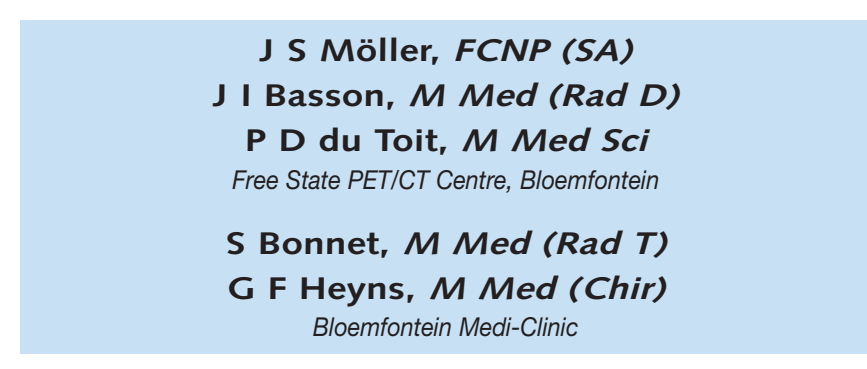

Positron emission tomography/computed tomography (PET/CT) with fluorine-18 fluorodeoxyglucose (F-18 FDG) is well established as a valuable tool in the staging and restaging of Hodgkin's and certain nonHodgkin's lymphomas, including the assessment of response to treatment. Previously, the recommendations of the International Working Group were widely implemented. ${ }^{1}$ Response criteria have recently been revised by the International Harmonization Project to include new developments such as PET/CT, immunohistochemistry and flow cytometry. ${ }^{2}$

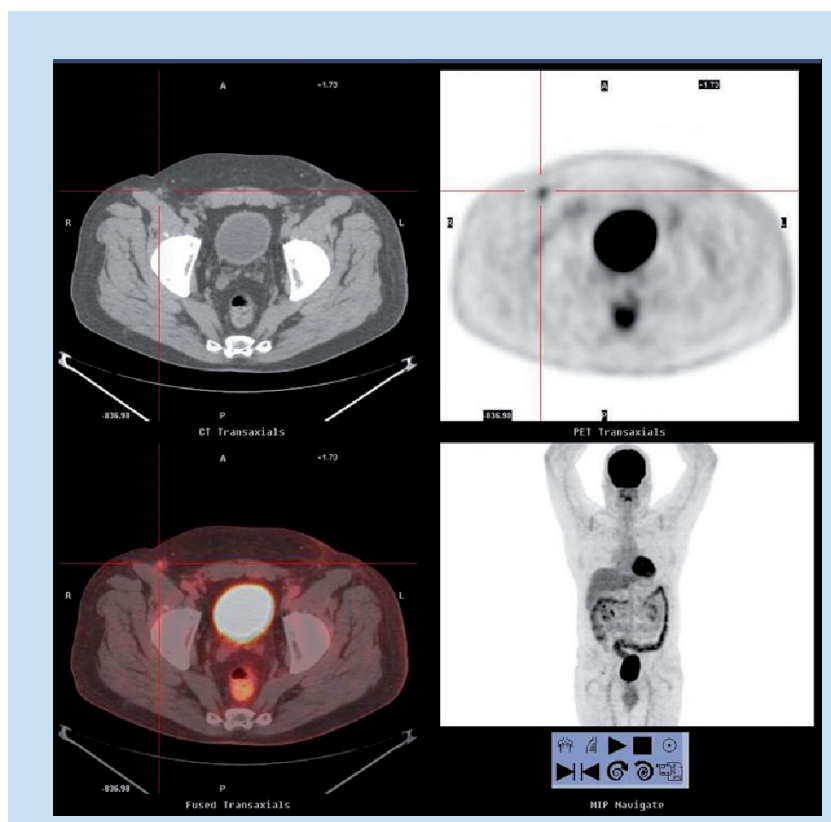

Fig. 1. Transaxial CT, PET and fusion images demonstrating a metabolically active sub-centimetre right inguinal lymph node.

We present the brief history of a 51-year-old man with follicular non-Hodgkin's lymphoma. Initial staging with PET/CT revealed involvement of lymph nodes above and below the diaphragm as well as the spleen (stage IIIS). He was subsequently treated with the R-CHOP

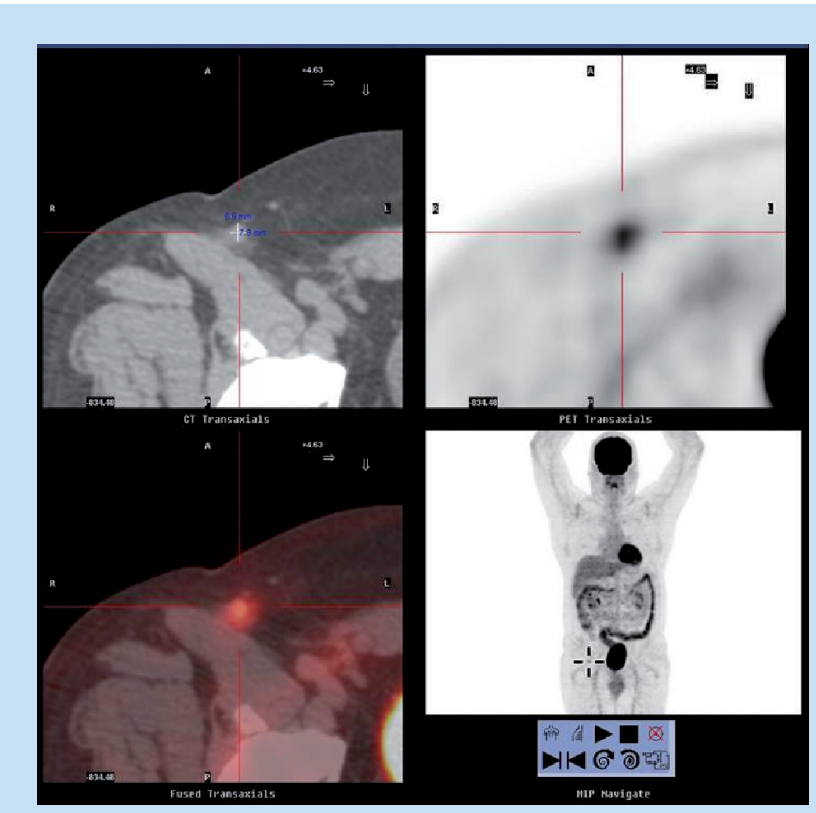

Fig. 2. Enlargement of the images above, with the measurements of the lymph node displayed $(6.9 \mathrm{~mm} \times 7.9 \mathrm{~mm})$.

regimen, with a clinically complete response. A follow-up PET/CT was performed to confirm the response to therapy and revealed a sub-centimetre $(6.9 \mathrm{~mm} \times 7.9 \mathrm{~mm})$ lymph node in the right inguinal region, not seen with the previous scan, with abnormal F-18 FDG uptake according to the revised criteria. ${ }^{3}$ A biopsy was performed, confirming the recurrence of lymphoma. The treatment plan was changed accordingly, from maintenance therapy with MabThera to involved field irradiation and thereafter consolidation with Zevalin.

This case demonstrates the limitations of using only size criteria to classify lymph nodes as normal or pathological. The introduction of F-18 FDG PET/CT overcame many of these limitations by providing information on both morphology and metabolism, and can be expected to provide the clinician with accurate information for response assessment in lymphomas, possibly leading to major changes in treatment and prognosis.

1. Cheson BD, Horning SJ, Coiffier B, et al. Report of an international workshop to standardize response criteria for non-Hodgkin’s lymphomas. J Clin Oncol 1999; 17: 1244-1253.

2. Cheson BD, Pfistner B, Juweid ME, et al. Revised response criteria for malignant lymphoma. J Clin Oncol 2007; 25: 579-586.

3. Juweid ME, Stroobants S, Hoekstra OS, et al. Use of positron emission tomography for the response assessment of lymphoma: consensus of the imaging subcommittee of the International Harmonization Project in Lymphoma. J Clin Oncol 2007; 25: 571-578. 